\section{The impact of foreign postings on accompanying military spouses: an ethnographic study}

\author{
Gillian Blakely, ${ }^{1}$ Catherine Hennessy, 1 \\ Man C. Chung, ${ }^{2}$ Heather Skirton ${ }^{1}$
}

1Faculty of Health, and Human Sciences, School of Nursing and Midwifery, Plymouth University, UK; ' ${ }^{2}$ Department of Psychology, Natural Science and Public Health, Zayed University, Dubai, United Arab Emirates

\section{Abstract}

As part of an ethnographic study, the impact of foreign postings on spouses who accompany military personnel was explored. Individual interviews and focus groups with 34 British military spouses based in one location in southern Europe were conducted. Key findings suggested that reaction to a foreign posting was a reflection of personal attitudes, prior experiences, support, ability to adjust to change and strength of relationship with the serving spouse and community. For many the experience was positive due to the increased opportunity for family time, for others this helped to compensate for the difficulties experienced. Some military spouses experienced significant distress on the posting, particularly if the family was not well-supported. The potential implications of military spouses not adapting to foreign postings have significant implications for healthcare practice. Provision of more appropriate support resources before and during the posting would facilitate the transition for the military spouse and their family.

\section{Introduction}

Geographical mobility can cause major upheavals in the lives of military families and relocations to foreign postings have been identified as imposing a significant strain on the family, especially the military spouse. 1,2 Whilst these spouses are recognized for their enduring ability to cope with extended periods of separation due to their serving spouses being posted away from home, there appears to be less understanding of the impact of relocation on military families when posted together to overseas locations. 1,3 One effect of frequent relocations is the interruption to established support networks, ${ }^{4}$ which normally contribute to the wellbeing of spouses and their families through providing appropriate resources. 5 The disruption of this familiar network in conjunction with an international posting presents further unique challenges to military spouses due to the supplementary stress of culture shock. ${ }^{6}$ Additional financial strains, limited spousal employment opportunities, extreme climate and communication difficulties are recognized as key areas of stress. ${ }^{7-9}$ However, enhanced family unity, travel and new cultural experiences are also cited as positive attributes of relocation. ${ }^{9-11}$

Burrell et al. reported that the health and wellbeing of individuals is affected by many social situations, ${ }^{1}$ therefore it is reasonable to suggest that relocation to unfamiliar surroundings can have an impact on an individual's health and lifestyle. In particular the perception of loss is identified as having a significant impact on military spouses' wellbeing. ${ }^{11}$ The accumulation of psychological losses is also noted by Makowsky et al. ${ }^{12}$ to intensify the stress of relocation, specifically through the loss of cherished relationships, personal identity and autonomy, causing significant distress. 13

Research investigating the experiences of non-military spouses (e.g. diplomatic, clergy or corporate spouses), who are also accustomed to frequent international relocations indicates that a successful foreign posting is at least partly dependent on their ability to adjust. ${ }^{12,14}$ Some individuals possess the necessary skills to acclimatize to overseas locations because of their previous experiences.9,11 However, the stoic response of other trailing spouses (a phrase highlighted by Keenan,15 to represent those who frequently relocate due to their husband or wife's employment) is identified as potentially detrimental to their health. ${ }^{3,11}$

The authors of the present study conducted a systematic review examining the experiences of military spouses on a foreign posting. ${ }^{16}$ The findings indicated that research investigating the specified topic was limited. Of 13 relevant papers, only three were completed in the last ten years with only Jervis's work representing British military spouses.1,9,11 Therefore, the present qualitative exploratory study was undertaken to address this gap in the literature with a view to explore ways to maximize spousal health and wellbeing. The aim of the study was to investigate the experience of the accompanying spouses of British military personnel relocated to a foreign country. The main research questions included: i) What is the emotional, social and psychological impact on spouses of British military personnel when relocated to a foreign country? ii) What methods are employed by the spouses to adjust to a new environment? iii) What types of emotional and social support are desired or used by spouses when living in a foreign community?
Correspondence: Gillian Carter (nee Blakely) School of Nursing and Midwifery, Queen's University Belfast, Medical Biology Centre, 97 Lisburn Road, Belfast, BT9 7BL, United Kingdom. Tel.: + 44.2890.975762.

E-mail: g.carter@qub.ac.uk

Key words: health professionals, international relocation, overseas, spouses, wellbeing.

Contributions: GB, HS, CH and MCC, study design; $\mathrm{GB}$ and $\mathrm{CH}$, data collection and analysis; $\mathrm{GB}, \mathrm{HS}$, $\mathrm{CH}$ and $\mathrm{MCC}$, manuscript writing.

Conflict of interests: the authors declare no potential conflict of interests.

Funding: this research was supported by a Faculty of Health, Education and Society PhD stipend awarded to Gillian Blakely.

Received for publication: 19 March 2013

Revision received: 9 May 2013.

Accepted for publication: 10 May 2013.

This work is licensed under a Creative Commons Attribution NonCommercial 3.0 License (CC BYNC 3.0).

(C) Copyright G. Blakely et al., 2014

Licensee PAGEPress, Italy

Health Psychology Research 2014; 2:1468

doi:10.4081/hpr.2014.1468

\section{Materials and Methods}

The design was an ethnographic study utilizing qualitative methods and was conducted from the perspectives of the military spouses on an overseas posting, with the intention of providing a holistic interpretation of their experiences. 17 The author GB was a military spouse and had spent a lengthy period within this environment, observing and participating in the daily lives of the British and Military communities. Undertaking fieldwork enabled the direct investigation of the experiences of the military spouse in context. As a participant observer GB's presence as a researcher was overt and as a military spouse was also an active member of the group. Therefore, recognizing and accounting for these roles was crucial to the research.

Ethnographic data collection consisted of semi-structured individual interviews and focus groups, in conjunction with researcher's field notes relating to these interviews and groups. The same schedule of open ended questions designed to explore the participants' understanding of experiencing an overseas posting was used for interviews and focus groups. These questions were developed from 
the themes identified in the systematic review, ${ }^{16}$ and from informal conversations and discussions with other military spouses prior to the commencement of the data collection (none of these data were used without consent). These questions reviewed: i) the initial reaction towards going on a foreign posting; ii) the subsequent impact of being on the posting and how individuals coped and adapted; iii) the factors influencing the ability to settle; iv) how their husband's role in the services influenced their overall experience; v) whether the presence or absence of children influenced their experience; vi) what support networks they felt were available; vii) if they felt they changed during the posting; viii) thoughts of returning to the United Kingdom (UK), and ix) advice for others about to go on a foreign posting. Interviews lasted approximately $60 \mathrm{~min}$ utes, while focus groups lasted between 1 and 2 hours.

Plymouth University ethics committee approved the study and ethics approval was also obtained from the Ministry of Defence. Adults married to a British military service person who was serving in a specified location in southern Europe were eligible for inclusion. Recruitment was via advertisements posted in the weekly online British Bulletin, on the community website, in the local British Community Centre and the Help, Information and Volunteer Exchange (HIVE). Purposive sampling was employed to obtain data from individuals with a range of characteristics to obtain a maximum variation sample. ${ }^{18}$ Therefore, it was necessary to advertise widely to ensure spouses of the three services were included in order to reach the potentially isolated groups. Eleven dimensions were chosen to establish a wide range of cases reflecting military spouses including the three service affiliations (Royal Navy, British Army and Royal Air Force); the role of the serving spouse (whether an officer or non-officer); and the stage of family cycle (i.e. the presence or absence of children).

Following the initial advertisement, each potential participant contacted the researcher and received an introductory letter and a participant information sheet. The researcher's contact details were provided and respondents were invited to ask further questions about the study. At the start of each focus group/interview, a further opportunity was given to ask questions and an advice sheet was provided in case any topic was considered too sensitive to discuss. If still happy to proceed, participants were asked to sign a consent form. The participant was made aware that they were under no obligation to proceed and could withdraw at any point without reason.

Data analysis was concurrent with data collection. Focus groups and interviews were conducted until it appeared that saturation had been reached i.e. when there was a repetition of themes and no new information was shared. ${ }^{19,20}$ Data were collected between July and October 2010. The focus groups and interviews were digitally recorded and transcribed verbatim. Data were analyzed using thematic content analysis, which initially involved the use of a coding system to break the text into segments. ${ }^{21}$ The text was coded in a line-byline process according to its meaning and content in relation to the objectives of the study, creating a bank of free nodes. Assessing for similarities and differences between these nodes then allowed grouping into a hierarchical tree structure, providing overarching themes. Specialist software for analyzing qualitative data, NVivo8 (QSR International), was used.

The analysis of the data was completed independently by GB and HS. Additionally, researcher field notes made immediately following each session and note-taker data recorded during the focus groups, improved the accuracy of the session transcriptions ensuring information was correctly matched, 22 and to facilitate data analysis.

\section{Results}

Thirty-four military spouses participated in 13 individual interviews (one conducted by email) and five focus groups. Each group consisted of between three and six individuals (totaling 22 participants, of which one chose to then complete an individual interview to provide more information - her data provided separate information for each analysis). The participants modal age range was 40-49, although all age groups from 18-29 to 50-59 were represented. One participant was male and the remainder were female. Twenty-two respondents were affiliated with the Royal Navy, six the British Army and six the Royal Air Force. Twenty-five of the respondents were officer spouses and the remainder were married to personnel of other ranks (see the Appendix for details; please note all participants have been assigned a pseudonym).

Thematic analysis of the data produced six themes: marriage and relationships; change; family lifestyle and wellbeing; acclimatizing to a new culture and social environment; personal meaning-making and individual differences; and support. The final two themes emerged from both focus groups and interviews and will be the focus of the following discussion.

\section{Theme 1: personal meaning-making and individual differences}

Acceptance of a new lifestyle induced by a foreign posting was influenced by the characteristics and personal qualities of the respon- dents, combined with previous experiences. Those respondents with prior experience of relocation and adjustment believed that they were more amenable to military postings. Furthermore, this made some respondents quite philosophical about their posting, ... you're so used to moving around and making the best of wherever we are ye know, you often don't realize the full impact until you've moved onto somewhere else (Naomi).

Individual responses to altered roles and identity were seen as a reflection of personal adaption to change. Activities such as academic studies, employment or simply through retaining some form of independence were seen as improving self-worth. Being proactive gave some respondents the justification they believed was needed to be on the posting as they did not want to be perceived as being idle. However, others expressed anger at the perceived loss of their autonomy: I just wish it wasn't so distinct that you are a wife of, a dependent of... and that most of the paperwork, most of the responsibility, most of the connection with what's going on in the community is . .., Adam's work, Adam's email, Adam's ye know everything (Abby).

Identity disorientation was heightened by being recognized as a dependent and having a lack of a defined societal role:... I don't like the word dependent I think... oh that's a bit demeaning isn't it, dependent? (Gemma). Also undermining was felt from the loss of career: ... I had my own job but yeh coming out here I am just a wife and mother (Hayley). Nonetheless, some participants acknowledged that being on the foreign posting was solely due to their wish to support their serving spouse and consequently accepted their military spouse status without complaint.

A further response to the posting was the generation of a changed perspective. This was accomplished through personal development and seeking experiences that were not part of the normal lifestyle. Indeed, some respondents were quite reflective about their overseas experience and recognized the personal opportunity it provided for their own development: ... it's just [a] very rich experience living in another country and learning (Caroline).

In general a spouse's attitude to the foreign posting was seen as a significant predictor of their willingness to adjust: in particular, embracing the available quality family time was seen to enhance the experience. Openmindedness and a certain vivacity were considered major constituents in adjusting successfully. Having a very proactive nature was also believed to stimulate a spouse's enthusiasm for the posting. The transference of this positive outlook on arrival was felt to consequently hasten the settling in process. 


\section{Theme 2: support prior, informal and formal}

Some spouses felt it was essential to investigate the new location prior to moving. Online information was the predominant resource and completing a reconnaissance visit (recce) provided crucial knowledge, allowing for the minimization of culture shock: ...you see all the horror that's here and then you come out with your eyes wide open and that shock isn't there (Wendy). However, recces were also felt to potentially discourage some, due to having an initial aversion to the area.

While the serving husband was considered to be the first line (Naomi) of support, forming a social network was recognized to be a key initial step of establishing an extended support system on the foreign posting. These sources enhanced respondents' ability to settle in a new environment, allowing the establishment of a secure surrounding. However, because of the nature of military life and frequent relocations, it was a common occurrence that newly formed friendships were lost, therefore social networks required active maintenance.

An opportune support network was available in the parco (walled in area containing villas) for some respondents on arrival and produced an opening into the community. Having these confidantes readily available offered empathic reassurance: We've all been there and everybody out here has had that experience ... so I think it is very supportive (Yvonne).

The lack of, or the inability to form a friendship network was identified as a substantial drawback for some wives. This concept of social isolation was a recognized phenomenon but was not always resolved: ... I have to say I am massively lonely here... I am just massively lonely and everyone else seems to have a social circle (Gail). Some respondents spoke of those who appeared to choose self-imposed isolation by remaining behind the doors of their homes however, it is not clear whether this was through choice for those individuals.

Children were perceived as a social catalyst for establishing friendship sets. However, this on occasion was seen to create artificial relationships, and in general the foreign posting was believed to force an unrealistic situation where friends were hastily formed. In parallel, not having children was felt to limit opportunities for forming a friendship network and left some feeling like recluses.

A recognized duty of the military was to provide a sponsor (an individual/ married couple currently on the foreign posting) to provide support to new arrivals. There was a general despondency as to the appropriateness of allocations, and the success of such pairings fluctuated greatly. While the military's facilitation of the relocation was welcomed by some respondents, this was not experienced by all and the general support provided by the mili- tary was alleged to be quite erratic. Consequently some attempted to resolve problems without any military involvement: I would be cautious about going to anybody in the authority because things ... can be blown out of proportion (Gail). It was also further alleged that spouses in general were disregarded: ...there is no respect, there's no respect for the spouses (Gail).

A certain level of reluctance existed with respect to seeking formal support whilst on the posting, due to concerns of distrust and alleged breaches of confidence within the welfare and medical services. The expressions really let down, nowhere to turn, [Beverly] and really hard to know who to trust [Helen], characterized this sense of extreme apprehension and disenchantment at the support offered. Compassionate leave however, for military spouses in times of family turmoil was deeply appreciated.

\section{Discussion}

This study was novel in that it focused specifically on the experiences of British Military spouses on an overseas posting, an area not previously given sufficient attention by researchers. ${ }^{16}$ Military spouses actually on a foreign posting shared their experiences and attitudes, and in doing so highlighted the potential challenges of accompanying their serving spouse overseas, which will now be discussed with reference to the study research questions.

\section{Research question 1}

The emotional, social and psychological effect of being relocated overseas is contingent upon the military spouse's ability to adapt to change. These findings concur with Hausman and Reed, ${ }^{23}$ who reported that some individuals experience relocation as a smooth transitional process, whereas for others such a significant change is a stressful event. As identified by Haour-Knipe, ${ }^{24}$ who examined how families coped both individually and together with the stress of moving to a new culture, there are additional stressors associated with an international move because of, for example, the potential language barriers, living in a new culture, social isolation, distance from family or climate change.

Social support is depicted as an exchange of resources intended to enhance wellbeing. ${ }^{25} \mathrm{As}$ identified in the present study for military families these links are frequently disrupted due to relocations. This is corroborated by Darcy, ${ }^{2}$ who investigated social support and the wellbeing of army wives following relocation. Darcy identified that removal of social support systems forced individuals to cope alone and interrupted their sense of belonging. Furthermore, Sluzki, ${ }^{26}$ discussed the impact of disrupting support networks due to relocation and identified a significant increase in emotional needs during this period, which was strongly linked with heightened psychosomatic and interpersonal stress.

The loss of employment and subsequent impact on identity and self-worth had a negative impact on the wellbeing of some study respondents. De Verthelyi, 27 who studied the adjustment process of international student spouses, felt that such a sense of loss was amplified on foreign relocations. Together these changes contributed to the overall loss of status and self-identity, ${ }^{28,29}$ and was a significant theme in the systematic review. ${ }^{16}$ In Kupka and Cathro's study examining German expatriate spouses, the obligatory dependency status and labeling as wife of was seen to revoke the spouse's right to individualism, ${ }^{30}$ as also identified in the present study. Undoubtedly changes of roles and personal identity influence the impact of a foreign posting and any subsequent adaption. According to Burke's Identity Disruption Theory, such disruptions occur in the identity process when individuals enter new cultures or assume new roles, ${ }^{13}$ as is the case of the trailing spouse. Consequently, there was a reduction of a person's perceived self-efficacy and of selfesteem, together heightening distress and the overall negative impact of the posting.

\section{Research question 2}

Examining the role of social support on spousal adjustment overseas, Copeland and Norell noted that women with the best adjustment were demonstrated to have an established support network. ${ }^{4}$ Nonetheless, the present study showed that feeling comfortable in a new environment was not necessarily directly proportional to the number of relationships formed. In an additional cross-cultural adjustment study by Norell and Copeland,31 having a strong marital relationship was also recognized as a significant predictor of adjustment. As such, from the perspective of the nonmilitary spouse, Wiggins-Frame and Shehan argued that clergy husbands were relatively consumed in their professional responsibilities, which may have resulted in a lack of support for their wives and children. ${ }^{14}$ A similar argument could be made in the case of military families.

Interactions of moderating factors can cause intercultural transitions to be complex processes.27 Hence, permutations of idiosyncratic variables could guide a reaction to an overseas posting. In the present study, respondents expressed the importance of having an outgoing, proactive nature. Furthermore, openness to experience was defined as a characteristic deemed to facilitate the cultural 
transition. 32 Accordingly, a positive relationship was suggested between the degree of openness and a spouse's level of adjustment, 33 and was seen to be related to resilience in sojourners. ${ }^{34}$

Comparable to the present study findings, expatriate spouses also regarded previous international experiences to be extremely beneficial for acculturation, ${ }^{32}$ and the self-reliance of such families was seen to increase with the number of previous overseas assignments. ${ }^{9}$ Therefore, greater exposure to unfamiliar environments could help to develop successful adaption strategies.

Study respondents felt quality family time compensated for the associated relocation disruption, but a positive experience was not inevitable. In particular foreign residence was found to have a significant negative relationship with a spouse's psychological and physical wellbeing.1,9 Additionally, as reported in the systematic review, 16 the likelihood of stoicism in military spouses was a concern and was felt to potentially have a detrimental impact on their health. ${ }^{3,11}$ Nonetheless, in the current study there was an innate determination by the respondents to remain on the posting and to support the serving member.

\section{Research question 3}

Support was a key theme identified in the systematic review recognizing its significance to spousal adjustment.16 The present study extended this finding by identifying the influence of personal meaning-making and individual circumstances on the level of support desired. Furthermore, comparable to the study findings, the provision of support prior to any international relocation was also reported by Mohr and Klein in their study exploring the experiences of expatriate spouses, to be crucial to limiting uncertainty and encouraging adjustment. ${ }^{32}$ However, Jervis considered that support offered by the military was only felt to represent what it deemed necessary. ${ }^{11}$ Nonetheless, the desire or need to access such support appeared to be a reflection of the study respondent's perception of the foreign posting and their own expectations.

Although no formal health assessments were conducted in this study, other research demonstrates the link between social support and a trailing spouse's wellbeing.,2,5,14,35 The protective effect of social support from psychosocial stress has been referred as a buffer. ${ }^{36}$ Cohen and McKay offered potential mechanisms responsible for the moderating effect of support reactions on a stressor. Of note, they presented an appraisal support mechanism founded on Lazarus and Folkman's stress and coping theory. ${ }^{37}$ Cohen and McKay believed a support group may influence the extent to which a situation was appraised as threatening and/or the individual's perception of their ability to cope. In accordance with Lazarus and Folkman's theory, when a stimulus is appraised as threatening and a subsequent appropriate coping response is unavailable, then a stress reaction occurs. ${ }^{37}$ Consequently, Cohen and McKay argue that, if there was a perception of available social support this could stimulate a less threatening appraisal of the situation, and result in the belief that an adequate response to the situation exists. ${ }^{36}$ In particular, Rosen and Moghadam investigated the stress-buffering effects of social support on military wives and concluded that perceived support from other unit wives was the only significant buffer. ${ }^{35}$ This study was specific to deployment separation anxiety; nonetheless it indicated the importance of close relationships during periods of turmoil, arguably such as international relocations. Therefore, it can be asserted that having access to a support network is pivotal for a trailing spouse's re-adjustment whilst preserving their wellbeing.

\section{Limitations}

Despite widespread advertising, one of the limitations of this study could be said to be the number of respondents who were officer spouses $(n=25)$ compared with the spouses of other ranks (non-commissioned status) $(n=9)$. Although a purposive sampling technique was used, potential participants may have been influenced to volunteer by the involvement of their personal contacts. Therefore, it is possible the experiences of the non-officer spouses could have been inadvertently under represented.

The cross-sectional sample represented participants based in only one foreign location. Therefore, the respondents' opinions could be biased by the particular base location, its facilities and the specific support structure that was available at time of the study. Future research could incorporate the views of military spouses based in other foreign locations in order to confirm or refute findings of this study. Finally, this was a qualitative study, therefore the use of a standardized instrument was not appropriate and the concept of generalizability does not apply. However, due to the rigor of the method, it is possible that the findings are transferable to other similar settings.

\section{Conclusions}

The thematic analysis identified numerous factors influencing a military spouse's ability to adapt to the changes imposed when on a foreign posting. Hence it would be inappropriate to suggest that the reaction to a foreign posting will be a positive experience for all, as this would ignore the complexities of an individ- ual's life. Failing to acclimatize to a new environment could have a significant social impact as well as a negative effect on the spouse's emotional and psychological wellbeing. Consequently, the strength of relationship with the serving spouse clearly has a significant supportive influence and it is this mutual devotion that not only compels the trailing spouse to accompany their spouse on the foreign posting but to also remain throughout despite any encompassing difficulties.

The findings of this study demonstrate the comparable reactions of accompanying military spouses to that of their civilian counterparts in previous non-military research. Whilst there appears to be a greater recognition of the influence of frequent international assignments for the non-military spouse due to the plethora of available research, the participants in this current phase of study clearly indicate that military spouses will also be prone to significant distress on a foreign posting, particularly if the family is not well-supported. Therefore, the potential health and wellbeing implications of a British military spouse not successfully adapting to a foreign posting has significant implications in the field of healthcare practice. Consequently, greater provision by the military and British community of support resources for the military spouse, both prior to relocation and on arrival at the foreign posting, would facilitate the transition for the entire family. Additionally, a more significant involvement of the accompanying spouse by the military during this period would allow them to regain some control of their new lifestyle and it could also signify a greater appreciation by the military of the military spouse's role in supporting the service person.

\section{References}

1. Burrell LM, Adams GA, Durand DB, Castro CA. The impact of military lifestyle demands on well-being, army, and family outcomes. Armed Forces Soc 2006;33:4358.

2. Darcy MG. Social support and relocation: an examination of the well-being of army wives. 2000. Available from: http://pearl.plymouth.ac.uk:8080/pearl_xm lui/bitstream/handle/10026.1/1949/MONICA\%20GORHAM\%20DARCY.PDF?sequenc $\mathrm{e}=1$

3. Fernandez-Pol B. Does the military family syndrome exist? Mil Med 1988;153:418-20.

4. Copeland AP, Norell SK. Spousal adjustment on international assignments: the role of social support. Int J Intercult Rel 2002;26:255-72.

5. Lavee Y, McCubbin HI, Patterson JM. The double ABCX model of family stress and 
adaptation: an empirical test by analysis of structural equations with latent variables. J Marriage Fam 1985;47:811-25.

6. Fisher CD, Shaw JB. Relocation attitudes and adjustment: a longitudinal study. $\mathrm{J}$ Organ Behav 1994;15:209-24.

7. Lakhani $H$. The socioeconomic benefits to military families of home-basing of armed forces. Armed Forces Soc 1994;21:113-28.

8. Manning FJ, DeRouin EM. Employed wives of US army members in Germany fare better than those unemployed. Mil Med 1981;146:726-8.

9. McNulty PA. Does deployment impact the health care use of military families stationed in Okinawa, Japan? Mil Med 2003;168:465-70.

10. Lakhani H, Thomas S, Gilroy C. Army european tour extension: a multivariate approach. J Behav Econ 1985;14:15-42.

11. Jervis S. Military wives and relocation: a psycho-social perspective. PhD dissertation. Bristol: University of the West of England; 2009.

12. Makowsky PP, Cook AS, Berger PS, Powell J. Women's perceived stress and wellbeing following voluntary and involuntary relocation. JFEI 1988;9:111-22.

13. Burke PJ. Identity processes and social stress. Am Sociol Rev 1991;56:836-49.

14. Wiggins-Frame M, Shehan CL. Work and well-being in the two-person career: relocation stress and coping among clergy husbands and wives. Fam Relat 1994;43:196-205.

15. Keenan B. Diplomatic baggage: the adventures of a trailing spouse. London: John Murray; 2006.

16. Blakely G, Hennessy C, Chung M, Skirton $\mathrm{H}$. A systematic review of the impact of foreign postings on accompanying spouses of military personnel. Nurs Health Sci 2011;14:121-32.

17. LeCompte M, Preissle J. Ethnography and qualitative design in educational research. 2nd Ed. London: Academic Press; 1993.

18. Stewart DW, Shamdasani PN. Focus groups: theory and practice. London: Sage; 1990.

19. Pope C, Ziebland S, Mays N. Qualitative research in health care: analysing qualitative data. BMJ 2000;320:114-6.

20. Cameron J. Focussing on the focus group. In: Hay I, ed. Qualitative research methods in human geography. Melbourne: 0xford University Press; 2005. pp 156-182.

21. Hammersley M, Atkinson P. Ethnography principles in practice. 3rd ed. New York: Routledge; 2007.

22. Wong LP. Focus group discussion: a tool for health and medical research. Singap Med J 2008;49:256-60.

23. Hausman MS, Reed JR. Psychological issues in relocation: response to change. $\mathrm{J}$ Career Dev 1991;17:247-58.

24. Haour-Knipe M. Moving families, expatriation, stress and coping. London: Routledge; 2001.

25. Shumaker SA, Brownell A. Toward a theory of social support: closing conceptual gaps. J Soc Issues 1984;40:11-36.

26. Sluzki CE. Disruption and reconstruction of networks following migration/relocation. Fam Syst Med 1992;10:359-63.

27. De Verthelyi RF. International students' spouses: invisible sojourners in the culture shock literature. Int J Intercult Rel 1995;19:387-411.

28. Shaffer MA, Harrison DA. Forgotten partners of international assignments: development and test of a model of spouse adjustment. J Applied Psychol 2001;86:238-54.
29. De Cieri H, Dowling PJ, Taylor KF. The psychological impact of expatriate relocation on partners. Int J Hum Resour Man 1991;2:377-414.

30. Kupka B, Cathro V. Desperate housewives - social and professional isolation of German expatriated spouses. Int $\mathbf{J}$ Hum Resour Man 2007;18:951-68.

31. Norell S, Copeland AP. US-UK moves: cross-cultural adjustment in american and british expatriate accompanying spouses 2002. Available from: http://www.interchangeinstitute.org/html/research_report s.htm\#british

32. Mohr AT, Klein S. Exploring the adjustment of American expatriate spouses in Germany. Int J Hum Resour Man 2004;15: 1189-206.

33. Caligiuri PM. Selecting expatriates for personality characteristics: a moderating effect of personality on the relationship bewteen host national contact and crosscultural adjustment. Manage Int Rev 2000; 40:61-80.

34. Arthur W, Bennet W. The international assignee: the relative importance of factors perceived to contribute to success. Pers Psychol 1995;48:99-114.

35. Rosen LN, Moghadam LZ. Matching the support to the stressor: implications for the buffering hypothesis. Mil Psychol 1990;2:193-204.

36. Cohen S, Mckay G. Social support, stress and the buffering hypothesis: a theoretical analysis. In: Baum A, Taylor SE, Singer JE, eds. Handbook of psychology and health. NJ: Hillsdale; 1984. pp 253-267.

37. Lazarus RS, Folkman S. Stress, appraisal and coping. New York: Springer; 1984. 